\title{
Correction to: Applications in Electronics Pervading Industry, Environment and Society
}

Sergio Saponara and Alessandro De Gloria

\section{Correction to:}

S. Saponara and A. De Gloria (eds.),

Applications in Electronics Pervading Industry, Environment and Society, Lecture Notes

in Electrical Engineering 573, https://doi.org/10.1007/978-3-030-11973-7

In the original version of the book, the following belated correction has been incorporated: The Volume number " 550 " has been changed to " 573 " in the book. 